\title{
A Study on Constraints being Perceived by the Farmers in Jaipur District of Rajasthan in Using Farm Television
}

\author{
Radhika Tanwar*, N.K. Sharma and Annu Devi Gora \\ Department of Extension Education, Sri Karan Narendra Agriculture University, Jobner, India \\ *Corresponding author
}

\author{
A B S T R A C T
}

\begin{tabular}{|l|}
\hline Key w ord s \\
Communication, \\
Information, \\
Sampling, \\
Television. \\
\hline Article Info \\
\hline $\begin{array}{l}\text { Accepted: } \\
\text { 30 June } 2017 \\
\text { Available Online: } \\
\text { 10 July } 2017\end{array}$ \\
\hline
\end{tabular}

In rural development nothing is more important than effective communication of farm information. In India where farmers live in less accessible and isolated villages communication is all the most difficult. In this situation television could be hopefully expected to cater to the needs of farm televiewers to a great extent. Television plays a very important role in the dissemination of farm information to the farmers. The present study was conducted in Jaipur region of Rajasthan which had Television Programme. Out of five districts in Jaipur region, Jaipur district was selected. From selected district, two panchayat samities (Dudu and Jhotwara) were selected randomly by using simple random sampling. From the selected panchayat samities 6 villages from each panchayat samiti were selected by using simple random sampling for study purpose similarly from 12 selected villages 120 respondents were selected by proportionate random sampling technique for study purpose. The investigator collected data by using personal interview method. The most important constraint faced by farmers "Irregular supply of electricity creating problem in seeking information from television" and the least important constraint faced by farmers "The timing of television programmes is not suitable for farmers".

\section{Introduction}

Agriculture is an important sector with the majority of the rural population in developing countries depending on it. The sector faces major challenges of enhancing production in a situation of dwindling natural resources necessary for production. Information and communication technologies (ICTs) play an important role in addressing these challenges and uplifting the livelihoods of the rural poor (Stienen et al., 2007).

ICTs refer to technologies people use to share, distribute, gather information and to communicate, through computers and computer networks" ICTs are a complex and varied set of goods, applications and services used for producing, distributing, processing, transforming information - [including] telecoms, TV and radio broadcasting, hardware and software, computer services and electronic media (Marcelle, 2000).

Television is the most powerful medium at present. Television can bring the world to our door steps within seconds. This mass medium has made dissemination of news, information and entertainment possible on a scale unprecedented in human society. T.V. is an ideal medium to convey information and news to illiterate and literate, urban and rural 
viewers on whom it would have profound impact. As an instructional device it is being used in variety of ways i.e. for direct teaching, for supplementary formal education, for developing psychomoter skills, for adult education and for diffusion of agriculture knowhow etc. It is expected that the rural oriented T.V. programmes can solve the problem of inaccessibility, illiteracy and shortage of skilled persons of India.

Therefore, keeping in mind the importance of T.V. in the field of agriculture the present study was conducted with the following objective: To identify the constraints being perceived by the farmers in using farm television.

\section{Materials and Methods}

\section{Study area}

The present study was conducted in Jaipur region of Rajasthan which had Television Programme, Jaipur. Out of five districts in Jaipur region, Jaipur district was selected. From selected district, two panchayat samities (Dudu and Jhotwara) were selected randomly by using simple random sampling. From the selected panchayat samities 6 villages from each panchayat samiti were selected by using simple random sampling for study purpose.

\section{Sampling procedure and sample size}

From 12 selected villages 120 respondents were selected by proportionate random sampling technique for study purpose.

\section{Data collection}

The investigator collected data by using personal interview method. The collected data were analyzed by using Mean Percent Score (MPS). The Mean percent scores were obtained by multiplying total obtained score of the respondents Kand divided by the maximum obtainable score under each practice. Formula of MPS is given as under:

MPS $=\frac{\text { Total score obtained by the respondent }}{\text { Maximum obtainable score }} \times 100$

\section{Results and Discussion}

\section{Constraints pertaining to effective utilization of farm T.V. programmes}

It is evident from data presented in table 1 that the most serious constraint perceived by the farm T.V. viewing farmers was "Irregular supply of electricity creating problem in seeking information from television" (MPS 89.72) as it was perceived to the highest extent by farmers. The second most perceived constraint in effective utilization of farm T.V. programmes was "Non participation of farmers in problem discussion" (MPS 88.72) followed by "Lack of prior information of the topics discussed" (MPS 85.00), "Lack of programmes relating to agriculture in local language" (MPS 81.11), "Illiteracy creates problems in understanding the new information" (MPS 78.89), "Visuals, specimens and written captions are shown once and for a shorter duration" (MPS 77.50), "Use of difficult technical terms" (MPS 74.17), which were ranked, Third, Fourth, Fifth, Sixth and Seventh, respectively.

While, "Television programmes do not cover the problems of the farmers of different strata" (MPS 71.66), "Inadequate skills" (MPS 60.00), "High cost of devices" (MPS 59.16), "Time allotted to farm is inadequate" (MPS 53.33), "Lack of reinforcement of programmes" (MPS 51.67) were found to be of 'medium extent' constraints which impede the effective utilization of the messages communicated to the viewing farmers through farm telecasts. However the constraints like "Contents are less need based" (MPS 49.95) and "The timing of television programmes is 
not suitable for farmers" (MPS 49.94) were found to be 'less serious' constraints in effective utilization of farm T.V. programmes. Jhajharia (2012) observed that the most serious constraint perceived by the farm viewing farmers was "Non participation of farmers in problem discussion" (MS 2.57) and "Inadequate time allocation (MS 1.62), was found to be less serious constraint in effective utilization of farm T.V. programmes.
Constraints pertaining to effective utilization of farm T.V. programmes in Dudu panchayat samiti

It is evident from data presented in table 1 that the most serious constraint perceived by the farm T.V. viewing farmers in Dudu panchayat samiti was "Non participation of farmers in problem discussion" (MPS 90.77) as it was perceived to the highest extent by farmers.

Table.1 Constraints pertaining to effective utilization of farm

T.V. programmes as perceived by the television viewing farmers

\begin{tabular}{|c|c|c|c|c|c|c|c|}
\hline \multirow[b]{2}{*}{ S.No. } & \multirow[b]{2}{*}{ Constraints } & \multicolumn{6}{|c|}{ Mean percent score } \\
\hline & & $\begin{array}{c}\text { Dudu } \\
n=60\end{array}$ & Rank & $\begin{array}{c}\text { Jhotwara } \\
\mathrm{n}=60\end{array}$ & Rank & $\begin{array}{c}\text { Overall } \\
n=120\end{array}$ & Rank \\
\hline 1. & $\begin{array}{l}\text { Illiteracy creates problems in } \\
\text { understanding the new information. }\end{array}$ & 80.00 & $\mathrm{~V}$ & 77.78 & $\mathrm{~V}$ & 78.89 & $\mathrm{~V}$ \\
\hline 2. & $\begin{array}{l}\text { Irregular supply of electricity is } \\
\text { create problem in seeking } \\
\text { information from television. }\end{array}$ & 90.55 & II & 88.89 & I & 89.72 & I \\
\hline 3. & $\begin{array}{l}\text { Television programmes do not cover } \\
\text { the problems of the farmers of } \\
\text { different strata. }\end{array}$ & 73.33 & VII & 70.00 & VIII & 71.66 & VIII \\
\hline 4. & $\begin{array}{l}\text { Lack of programmes relating to } \\
\text { agriculture in local language. }\end{array}$ & 81.11 & IV & 81.11 & IV & 81.11 & IV \\
\hline 5. & $\begin{array}{l}\text { The timing of television programmes } \\
\text { is not suitable for farmers. }\end{array}$ & 43.88 & XIV & 50.00 & XIII & 46.94 & XIV \\
\hline 6. & High cost of devices & 60.00 & $\mathrm{X}$ & 58.33 & $\mathrm{X}$ & 59.16 & $\mathrm{X}$ \\
\hline 7. & Inadequate skills & 60.55 & IX & 59.44 & IX & 60.00 & IX \\
\hline 8. & $\begin{array}{l}\text { Non participation of farmers in } \\
\text { problem discussion }\end{array}$ & 90.77 & I & 86.67 & II & 88.72 & II \\
\hline 9. & Contents are less need based & 48.89 & XIII & 45.00 & XIV & 46.95 & XIII \\
\hline 10. & $\begin{array}{l}\text { Visuals, specimens and written } \\
\text { captions are shown once and for a } \\
\text { shorter duration }\end{array}$ & 78.89 & VI & 76.11 & VII & 77.50 & VI \\
\hline 11. & Use of difficult technical terms & 71.11 & VIII & 77.22 & VI & 74.17 & VII \\
\hline 12. & $\begin{array}{l}\text { Lack of reinforcement of } \\
\text { programmes }\end{array}$ & 51.11 & XII & 52.22 & XII & 51.67 & XII \\
\hline 13. & Time allotted to farm is inadequate & 52.77 & XI & 53.89 & XI & 53.33 & XI \\
\hline 14. & $\begin{array}{l}\text { Lack of prior information of the } \\
\text { topics discussed }\end{array}$ & 86.11 & III & 83.89 & III & 85.00 & III \\
\hline & Overall & 69.37 & & 68.61 & & 68.99 & \\
\hline
\end{tabular}


The second most perceived constraint in effective utilization of farm T.V. programmes was "Irregular supply of electricity creating problem in seeking information from television" (MPS 90.55) followed by "Lack of prior information of the topics discussed" (MPS 86.11), "Lack of programmes relating to agriculture in local language" (MPS 81.11), "Illiteracy creates problems in understanding the new information" (MPS 80.00), "Visuals, specimens and written captions are shown once and for a shorter duration" (MPS 78.89), "Television programmes do not cover the problems of the farmers of different strata" (MPS 73.33), which were ranked, Third, Fourth, Fifth, Sixth and Seventh, respectively. While, "Use of difficult technical terms" (MPS 71.11), "Inadequate skills" (MPS 60.55), "High cost of devices" (MPS 60.00), "Time allotted to farm is inadequate" (MPS 52.77), "Lack of reinforcement of programmes" (MPS 51.11) were found to be of 'medium extent' constraints which impede the effective utilization of the messages communicated to the viewing farmers through farm telecasts. However the constraints like "Contents are less need based" (MPS 48.89) and "The timing of television programmes is not suitable for farmers" (MPS 43.88) were found to be 'less serious' constraints in effective utilization of farm T.V. programmes for Dudu panchayat samiti's farmers.

Constraints pertaining to effective utilization of farm T.V. programmes in Jhotwara panchayat samiti

It is evident from data presented in table 1 that the most serious constraint perceived by the farm T.V. viewing farmers of Jhotwara panchayat samiti was "Irregular supply of electricity creating problem in seeking information from television" (MPS 88.89) as it was perceived to the highest extent by farmers. The second most perceived constraint in effective utilization of farm T.V. programmes was "Non participation of farmers in problem discussion" (MPS 86.67) followed by "Lack of prior information of the topics discussed" (MPS 83.89), "Lack of programmes relating to agriculture in local language" (MPS 81.11), "Illiteracy creates problems in understanding the new information" (MPS 77.78), "Use of difficult technical terms" (MPS 77.22), "Visuals, specimens and written captions are shown once and for a shorter duration" (MPS 76.11), which were ranked, Third, Fourth, Fifth, Sixth and Seventh, respectively. While, "Television programmes do not cover the problems of the farmers of different strata" (MPS 70.00), "Inadequate skills" (MPS 59.44), "High cost of devices" (MPS 58.33), "Time allotted to farm is inadequate" (MPS 53.89), "Lack of reinforcement of programmes" (MPS 52.22) were found to be of 'medium extent' constraints which impede the effective utilization of the messages communicated to the viewing farmers through farm telecasts. However the constraints like "The timing of television programmes is not suitable for farmers" (MPS 50.00) and "Contents are less need based" (MPS 45.00) were found to be 'less serious' constraints in effective utilization of farm T.V. programmes for Jhotwara panchayat samiti's farmers.

Based on the findings of the study, it may be concluded that the most important constraint faced by farmers "Irregular supply of electricity creating problem in seeking information from television" (MPS 89.72) and the least important constraint faced by farmers "The timing of television programmes is not suitable for farmers" (MPS 49.94).

\section{Recommendations}

The present timing of the farm T.V. programmes specially 'Krishi Darshan' should be at 8.00 P.M. in summer and 7.00 
P.M. in winter. The duration of farm T.V. programmes especially 'Krishi Darshan' should be increased by 10 to 15 minutes. The farm T.V. programmes should be designed as per the need and problems of the farmers.

\section{Suggestions for future research}

The study was conducted only in two panchayat samities of Jaipur district of Rajasthan. The area of research could be extended further and sufficiently large number of sample should be studied to draw more valid conclusions. Farm T.V. programmes should be made on the needs and problems of farmers. More emphasis should be given on proper timing, local crops and local language in farm T.V. programmes.

\section{References}

Jhajharia, A.K., Khan, I.M., Bangarva, G.S. and Jhajharia, S. (2012). "Awareness of farmers about farm based radio and television programmes". Rajasthan Journal Extension Education 20: 209214, 2012.

Marcelle, G. (2000). Gender, Justice and ICTs. Available at http://www.un.org/womenwatch/daw/cs w/marcelle.htm.

Stienen, J., Bruinsma, W. and Neuman, F. (2007). How ICT can make a difference in agricultural livelihoods. Published in "The Commonwealth" minister's reference Book. 2-4.

\section{How to cite this article:}

Radhika Tanwar, N.K. Sharma and Annu Devi Gora. 2017. A Study on Constraints being Perceived by the Farmers in Jaipur District of Rajasthan in Using Farm Television. Int.J.Curr.Microbiol.App.Sci. 6(7): 4396-4400. doi: https://doi.org/10.20546/ijcmas.2017.607.458 